\title{
How can mariculture better help feed humanity?
}

\author{
Yngvar Olsen * \\ Trondhjem Biological Station, Department of Biology, Norwegian University of Science and Technology, Trondheim, Norway
}

Keywords: mariculture, global food production, global food security, strategy for expansion, roadmap for mariculture

The primary production of the marine and the terrestrial domains are similar, $\sim 49$ and $56 \mathrm{Gt}$ C year ${ }^{-1}$, respectively (Field et al., 1998), and the marine primary production must likely be more readily available for grazing animals because it is primarily in the form of unicellular phytoplankton. We harvest the ocean quite efficiently, perhaps beyond its sustainable yields (Marra, 2005), and it is therefore surprising that only some 2\% of human food are from aquatic systems, including marine and freshwater aquaculture and fisheries (Figure 1A, faostat3.fao.org and fao.org/fishery/statistics/en). This number is valid for total weight based food production. For animal meat and for animal products totally (milk and egg included), the aquatic food acquisition is more important, contributing 34 and 12\%, respectively, of the total production in terrestrial and aquatic systems (Figures 1A-C).

The combined production of global aquaculture in the sea and in freshwater is currently similar to that harvested from the sea (Figure 1B). As much as $96 \%$ of the plant production is from marine aquaculture, or mariculture, whereas $44 \%$ of the total fish production is cultured. Fish is totally dominant in freshwater aquaculture ( $>99 \%)$.

The production of seaweed has increased most rapidly over the last two decades (Olsen, 2011, fao.org/fishery/statistics/en) and the production is presently similar to the sum of mollusks, crustacean and fish (Figure 1C). The production of mollusk has also increased rapidly while crustaceans and fish that need to be fed have increased slower over many decades. There is already a relatively severe limitation in the availability of feed resources of marine origin needed for fish and crustaceans, because almost all species maintained in intensive production are provided with some marine resources in their feed (Tacon and Metian, 2008). Agricultural plant products have gradually been included in feed for fish and shrimps over the last two decades, now representing a substantial type of resources in the feed for these carnivores (Olsen, 2011).

It is an ultimate challenge and question if agriculture can supply the food needed by the increasing global human population in the 21st Century, reaching 9.5 (8.3-10.9) billion by 2050 (UN, 2012a), a population showing a steadily increasing buying power. Among the main concerns is supply of freshwater (Oki and Kanae, 2006; Duarte et al., 2009), availability of phosphate as fertilizers (Cordell and White, 2014), new space needed for increasing production, environmental interactions and climate change (UN, 2012b; FAO, 2014), raising doubts about global food security in the decades to come (Miller, 2008). It is because of this situation and the "food crisis" in 2008 that many, including FAO and the Rio +20 conference, encourage fisheries and mariculture to take a more prominent role in human food security (UN, 2012b; FAO, 2014).

Terrestrial agriculture is today far more important than marine food acquisition, and this originate in a major difference in the human seafood chain and agriculture food chain, a difference often not considered (Duarte et al., 2009). With a comparable input of primary production (Field et al., 1998), the low seafood provision from mariculture and fisheries as compared to that from agriculture is a consequence of the additional trophic levels in the oceans (Ryther, 1969). Humans feed in fact around two steps higher in the seafood chain than in the agriculture food chain (Duarte et al., 2009; Olsen, 2011). This fact is likely the main reason why only 


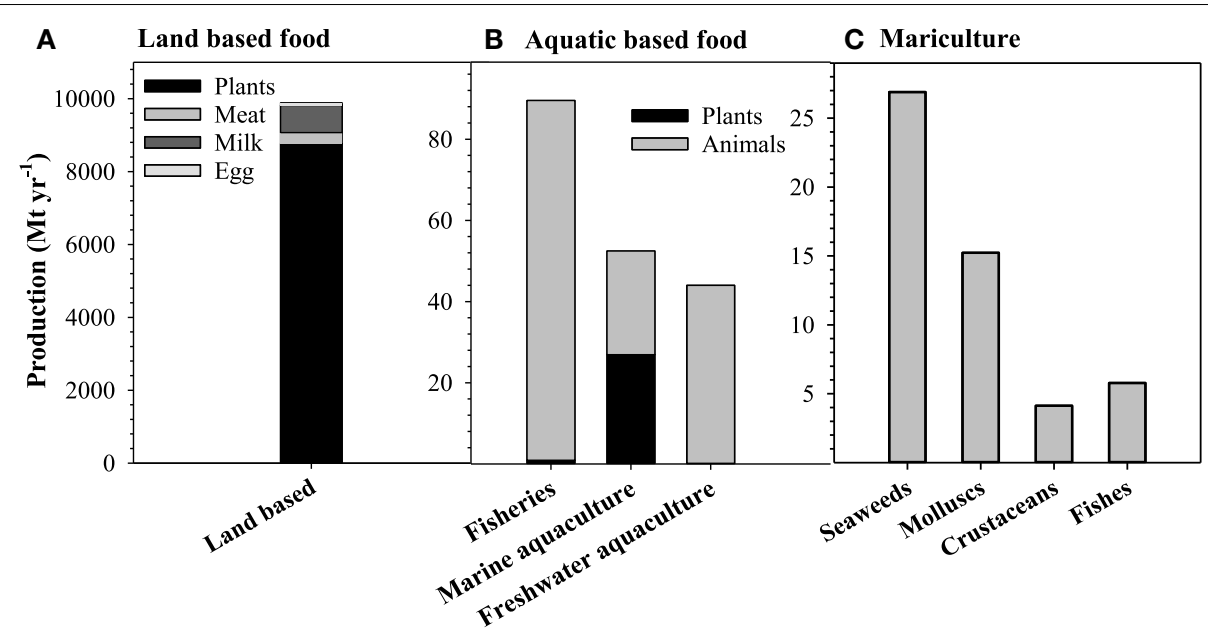

FIGURE 1 | Food production with its main components in agriculture (A), plant and animal production in different aquatic systems (B) and the overall composition of main groups produced in mariculture (C). Note the different scales of the $y$-axis (Mt, megatons or million tons).

$1.4 \%$ of our food comes from the marine domain, or totally $1.9 \%$ comes from aquatic systems (Figure 1). It is a main challenge to reduce, if not close, that gap. The metabolic losses originating from a high number of trophic transfers must then be reduced, and mariculture opens several options to reduce these losses which are not available in fisheries. The challenge has scientific, technological and social implications, interacting with policy questions regarding natural resources. It is a great challenge for the aquaculture industry, science and society in the 21 st Century.

A general objective of developing mariculture is accordingly to continue increasing seafood production in mariculture by reducing the number of trophic transfers in the seafood chain, meaning that cultured animals, and thereby also humans, should be moved to lower trophic levels in the seafood chain. The increased production must not compromise functional ecosystems and biodiversity (UN, 2012b; FAO, 2014). All human activities have environmental costs, but the influence must be kept within acceptable limits.

The objective is clear and it will become paramount that Governments of coastal states, all involved stakeholders and society must support that development. Known constraints for the further development and expansion of mariculture involve legal questions, technology, feed resources, coastal space, environmental interactions and an efficient infrastructure, and new upcoming constraints will likely appear.

An overall strategy for developing mariculture should be based on a roadmap for how this objective can be achieved. It is important to note that this development toward reducing the number of trophic transfers in the seafood chain is already ongoing, but it is normally not thought of in terms of shortening the seafood chain. Seaweeds and mollusks farming are the fastest growing sectors in global mariculture, showing that the production in mariculture already for two decades has developed toward lower trophic levels. Moreover, the feed resources used for farmed carnivore animals are increasingly coming from agricultural plants (Naylor et al., 2009; Kaushik and Troell, 2010; Olsen, 2011), and because of this, carnivore fish are already moved more than one trophic level down in the food chain as compared to their wild stocks (Olsen, 2011). It is likely that mariculture and aquatic food production can only become more important relative to terrestrial agriculture if the ratio plants:animals produced in mariculture (1.1 in 2013) becomes more similar to that in agriculture (7.7) (Lovatelli et al., 2013), because there are obvious resource limitations for production of carnivore animals in the sea. More seaweed production is needed to include more seaweed products in the feed of cultured marine animals, and this will likely also result in more use of seaweed for human food, like in many Asian countries.

The fundamental aspects above have implications for all common scientific issues of aquaculture, and an overall general strategy of developing mariculture might among others involve:

- Culture of more low trophic level species or groups (e.g., omnivore fish, mollusks and seaweed).

- Bring carnivore fish and crustaceans to lower trophic level by using more feed resources from low trophic level, e.g., seaweed, microbes, plants and other non-fish resources.

- Use the available fish meal and fish oil in an optimal way, the available quantity will likely become reduced with time.

- Strive for more ecological thinking in mariculture, the wastes of one organism is the food for another, integrate cultures.

- Comply with regulations to reduce and control environmental interactions of mariculture, at cultivation sites and in the entire life cycle of mariculture.

- Adopt established technology and systems from current aquaculture practices to new systems and organisms, including production systems, methods of cultivation, and health and welfare management. 
The challenge of preparing feeds for carnivore animals based on plant or ingredients from cultures of microbes is not trivial; a nutritionally adequate feed for fish must contain sufficient amounts of marine lipids with long chain, highly unsaturated fatty acids (e.g., DHA), which are important for human health and only abundant in aquatic food chains (Olsen, 2011). This challenge has been less in agriculture where the domesticated animals are herbivore. The dominant species and groups produced in future mariculture will likely depend on our ability to establish new feed resources with a marine lipid profile. There are few attractive herbivore fish species in the marine environment, and extractive organisms like mollusks and seaweed will become more dominant if feed resources become even more limiting.

In the efforts to derive new feed resources, an overall aim should also be to establish resources that are not major components of the human food chain (e.g., taken from today's commodity markets) and to take most of these new resources from the sea in order to establish a more self-sufficient mariculture food chain on a longer time perspective (Duarte et al., 2009; Lovatelli et al., 2013). It should not be taken for granted that society will accept that agricultural food products for human food are used widely for animal production in the future.

In a scenario of expanding production, it is important that most coastal nations have non-protected coasts and will need aquaculture production systems for exposed coastal waters, which is generally not commercially established. The production of juvenile plants and animals will still normally be undertaken in land based or protected sea locations, and reuse of water and saving of energy for heating water has become important issues. For many regions and costal states, the questions on available coastal space together with international legislation that regulates commercial activities in international waters is an important consideration, bringing in aspects of governance (Lovatelli et al., 2013).

Other questions regarding mariculture expansion involve species and group diversification, biology and zoo-techniques

\section{References}

Cordell, D., and White, S. (2014). "Life's bottleneck: sustaining the world's phosphorus for a food secure future," in Annual Review of Environment and Resources, Vol. 39, eds A. Gadgil and D. M. Liverman (Palo Alto, CA: Annual Reviews), 161-188. doi: 10.1146/annurev-environ-010213-113300

Duarte, C. M., Holmer, M., Olsen, Y., Soto, D., Marba, N., Guiu, J., et al. (2009). Will the oceans help feed humanity? Bioscience 59, 967-976. doi: 10.1525/bio.2009.59.11.8

FAO. (2014). The State of World Fisheries and Aquaculture. Opportunities and Challenges. Rome. Available online at: http://www.fao.org/fishery/sofia/en

Field, C. B., Behrenfeld, M. J., Randerson, J. T., and Falkowski, P. (1998). Primary production of the biosphere: integrating terrestrial and oceanic components. Science 281, 237-240. doi: 10.1126/science.281.5374.237

Kaushik, S. J., and Troell, M. (2010). Taking the fish-in fish-out ratio a step further. Aquacult. Eur. 35, 15-17.

Liu, Y., Olaussen, J. O., and Skonhoft, A. (2011). Wild and farmed salmon in Norway. A review. Mar. Policy 35, 413-418. doi: 10.1016/j.marpol.2010.11.007 for cultivation, feeding and nutritional requirements, efficiency in feed utilization, and health and welfare issues for new and already cultured groups and species. These are questions raised in aquaculture research and development in recent times, and are still important for a further expansion. New enabling technologies and methods of biotechnology, including industrial biotechnology, will likely become important for developing mariculture. Other important enabling technologies involve material technologies (e.g., nano-technology) and aspects of information technologies, and modeling of processes will continue to develop.

Dependent of hydrodynamic and other water use, mariculture activities may interact with the marine environment. Pollution from other industries and densely populated urban settlements may threat seafood safety. Aquaculture sites release metabolic wastes and sometimes also toxic compounds, for example components originating from pharmaceutical agents. Both environmental- and resource footprints of mariculture revealed through impact studies and life cycle studies are important, including the influence of and on the global carbon cycle and climate. These issues, as well as genetic and disease aspects related to escapes of farmed organisms, bring in aspects of economy, management and governance as specific challenges faced by mariculture worldwide (e.g., see Liu et al., 2011).

The food production level of global mariculture can only approach that in agriculture if the number of trophic transfers and the metabolic losses in the seafood chain can be reduced, which means that humans eating seafood are moved to lower trophic levels (Duarte et al., 2009; Olsen, 2011). Such changes have as mentioned characterized developments in mariculture already for a decade or two, and must continue. Joining forces and taking the right steps, it is a reasonable expectation that the protein production in the sea will exceed that in agriculture (Duarte et al., 2009). If the total production in mariculture continues to grow by $6-7 \% \mathrm{yr}^{-1}$ as through $2000-2013$, it will reach 5-600 Mt by 2050 .

Lovatelli, A., Aguilar-Manjarrez, J., and Soto, D. (2013). "Expanding mariculture farther offshore. Technical, environmental, spatial and governance challenges," in FAO Technical Workshop, Orbetello, Italy, 22-25 March 2010, (Rome: Food and Agriculture Organization of the United Nations).

Marra, J. (2005). When will we tame the oceans? Nature 436, 175-176. doi: $10.1038 / 436175 a$

Miller, F. P. (2008). After 10,000 years of agriculture, whither agronomy? Agron J. 100, 22-34. doi: 10.2134/agrojnl2007.0013

Naylor, R. L., Hardy, R. W., Bureau, D. P., Chiu, A., Elliott, M., Farrell, A. P., et al. (2009). Feeding aquaculture in an era of finite resources. Proc. Natl. Acad. Sci. U.S.A. 106, 15103-15110. doi: 10.1073/pnas.0905235106

Oki, T., and Kanae, S. (2006). Global hydrological cycles and world water resources. Science 313, 1068-1072. doi: 10.1126/science.11 28845

Olsen, Y. (2011). Resources for fish feed in future mariculture. Aquacult. Environ Interact. 1, 187-200. doi: 10.3354/aei00019

Ryther, J. H. (1969). Photosynthesis and fish production in the sea. Science 166, 72-76. doi: 10.1126/science.166.3901.72 
Tacon, A. G. J., and Metian, M. (2008). Global overview on the use of fish meal and fish oil in industrially compounded aquafeeds: trends and future prospects. Aquaculture 285, 146-158. doi: 10.1016/j.aquaculture.2008. 08.015

UN. (2012a). United Nations - World Population Prospects: The 2012 Revision Population Database, 4th of May 2015. Available online at: http://esa.un.org/ wpp/unpp/panel_population.htm

UN. (2012b). "The future we want," in Outcome document of the United Nations Conference on Sustainable Development, 20-22 June 2012 (Rio de Janeiro). Available online at: http://www.un.org/en/sustainablefuture/
Conflict of Interest Statement: The author declares that the research was conducted in the absence of any commercial or financial relationships that could be construed as a potential conflict of interest.

Copyright $(\odot) 2015$ Olsen. This is an open-access article distributed under the terms of the Creative Commons Attribution License (CC BY). The use, distribution or reproduction in other forums is permitted, provided the original author(s) or licensor are credited and that the original publication in this journal is cited, in accordance with accepted academic practice. No use, distribution or reproduction is permitted which does not comply with these terms. 